\title{
Hear Today, Gone Tomorrow: An Assessment of Portable Entertainment Player Use and Hearing Acuity in a Community Sample
}

\author{
Samit Shah, BS, Bharat Gopal, MD, Janet Reis, PhD, and Michael Novak, MD
}

Background: Noise-induced hearing loss (NIHL) is a common but preventable disability. The purpose of this study was to assess the understanding of NIHL in a community sample in the context of exposure to portable music players, including MP3 players, and personal hearing acuity as tested with the Welch Allyn Audioscope 3.

Methods: A cross-sectional convenience sample of 94 adults (18 to 65 years old) at a university recreation center completed an analysis of personal use of portable digital music players (MP3 players), concerns about hearing loss, and a 3-dB-level hearing test at 4 levels of speech frequency in a low ambient noise setting.

Results: The majority of participants $(85 \%)$ were concerned about hearing loss, willing to protect their hearing with lower volume (77\%), had little measurable hearing loss but were exposed to longer and louder periods of noise than other national samples, and mistakenly felt that NIHL is a medically reversible condition. Many (40\%) also wanted their family medicine physician to be more concerned about their hearing.

Conclusions: Family medicine physicians are in a key position to provide basic information on the preventability and negative consequences of NIHL, as well as to identify and refer patients with identified hearing loss. (J Am Board Fam Med 2009;22:17-23.)

Noise-induced hearing loss (NIHL) is the most frequently occurring preventable disability and can be caused by recreational or occupational sources of sound, as evidenced by the nearly 22 million Americans between the ages of 20 and 69 who have irreversibly damaged hearing because of excessive noise exposure. ${ }^{1}$ National hearing screening tests have identified an increase in hearing problems for children at ever younger ages, suggesting that new sources of noise may already be impacting the hearing of young people. ${ }^{2}$

Proper auditory function depends on the transmission of mechanical sound energy from the external environment, through the ear and brainstem,

This article was externally peer reviewed.

Submitted 8 February 2008; revised 18 July 2008; accepted 22 July 2008.

From the Medical Scholars Program, College of Medicine (SS), and the Department of Family Medicine (BG, JR), University of Illinois at Urbana-Champaign (SS); and the Department of Otolaryngology, Carle Clinic Association, Urbana, IL (MN).

Funding: University of Illinois at Urbana-Champaign

College of Medicine and Carle Foundation Hospital.

Conflict of interest: none declared.

Corresponding author: Bharat Gopal, MD, Carle Family Medicine Residency, 602 West University Avenue, Urbana, Illinois 61822 (E-mail: bharat.gopal@carle.com). to cortical processing centers. Pathology can occur at any point in the auditory pathway, and the defect can range from a mild conductive loss to severe sensorineural hearing loss and profound deafness. Chronic noise exposure damages sensory hair cells in the cochlea, which are responsible for stimulating the auditory nerve. The resulting sensorineural hearing loss is characterized by a primary loss of the hair cells and the subsequent degeneration of auditory nerve processes. Diagnostic measures based on sound perception (such as the audiometry used in this study) do not specifically evaluate hair cell function, so damage is often not noticed until an irreversible perceptual deficit arises. $\mathrm{Pa}$ tients with mild sensorineural hearing loss can be treated with hearing aids, but severe sensorineural loss can only be treated with cochlear implantation. The permanence of noise-induced hearing loss emphasizes the importance of the prevention of noise damage.

The increasing availability of portable music/ entertainment players (PMPs) raises questions about the way these devices are being used, consequences for hearing, and general awareness of the potential for damage from such equipment. ${ }^{3-7}$ To 
date, evidence supporting the relationship between PMP use and hearing damage is mixed. ${ }^{8,9}$ However, it is well documented that damage to the auditory system is a cumulative process and that once injury from loud noise is sufficiently severe enough to be measured, the loss is substantial and irreversible. $^{10,11}$

There have been several recent surveys regarding the self-reported use of earphones and portable entertainment devices and concerns about use. ${ }^{12,13}$ However, there are no recently published reports focusing on the use of portable entertainment devices that survey the potential for and concern about hearing damage as assessed against actual hearing acuity.

The purpose of this study is to summarize the findings from a brief screening performed at a large Midwestern University consisting of volunteer feedback about listening habits and a free assessment of hearing acuity from a handheld audiometer. The project was developed as an introduction to applied clinical research for first- and secondyear medical students and sponsored by a Family Medicine program.

\section{Methods \\ Subjects}

All participants were recruited from a campus recreation facility in early evening hours where many facility users arrive with some version of a PMP to use during exercise. Ninety four volunteers participated in the study, representing approximately $25 \%$ of individuals entering the facility during the study period; $42 \%$ were undergraduate students (58\% male, $32 \%$ female), $39 \%$ (54\% male, $46 \%$ female) were graduate students, and the rest were faculty or staff ( $68 \%$ male, $32 \%$ female). A booth in the lobby advertised a "hearing study." Individuals who agreed to the terms of the study were presented with a letter of informed consent, as approved by the University Institutional Review Board. After the consent process, participants completed a 20-item questionnaire and a hearing test was performed. All responses were anonymous.

\section{Measures}

A 20-item questionnaire was constructed drawing in part from the "Survey of Teens and Adults about the Use of Personal Electronic Devices and Head Phones."13 Included from this survey were ques- tions on experiences with conditions of hearing loss, types of entertainment devices used, length of time and intensity of volume when listening to portable entertainment devices, concerns of hearing loss from use of these devices, and concerns for hearing loss with aging. Also included in the survey were questions of whether people had heard of NIHL and, if so, whether NIHL is believed to be reversible with medical treatment.

A Welch Allyn AudioScope 3 (Skaneateles Falls, NY) was used to test hearing acuity. This audiometer provides screening at speech frequencies of 500, 1000, 2000, and $4000 \mathrm{~Hz}$ at fixed decibel (dB) levels on a hearing level (HL) scale. In this study, the detection of a pure tone at 3 sound intensities was tested (20 dB HL, $25 \mathrm{~dB}$ HL, and $40 \mathrm{~dB} \mathrm{HL})$ at 4 frequency levels known to be necessary for the understanding of speech. ${ }^{14}$ The AudioScope presents tones randomly to ensure objectivity. The Audioscope 3 also provides a $1000-\mathrm{Hz}$ pretone, presented at $20 \mathrm{~dB}$ HL above the screening level, as a practice session. The pretone is followed by the easiest tone, beginning with $1000 \mathrm{~Hz}$, to enhance the reliability of the response.

Testing was performed in a small quiet room by a second-year medical student under the supervision of the second author. The ambient background noise in the testing room was measured using a Bruel \& Kjaer (Denmark) type 2239 Integrating Sound Pressure Level meter. The A-weighted intensity of the background noise was $40 \mathrm{dBA}$ across the frequency spectrum. (A-weighting is the most widely used standard for the assessment of environmental noise.) Because the measured level is well below the threshold for background noise established by Welch Allyn (55 $\mathrm{dBA})$, the results of the hearing screening were not effected by the ambient noise in the room. ${ }^{15}$

The audiometer was aseptic and was thoroughly sanitized after each test. Levels of cerumen were visually observed and recorded on a 4-point scale. At the conclusion of the screening, all participants received an informational brochure about the prevention of noise-induced hearing loss with a summary of the results of their hearing test.

\section{Data Analysis}

The $\chi^{2}$ statistic was used to test the association between university status (undergraduate, graduate, faculty, staff), gender, and predisposing factors for an increased risk of developing noise-induced hear- 
Table 1. Percent of Subjects Within Each Academic Level Indicating Risk Factors for Noise Induced Hearing Loss According to Gender $(\mathrm{n}=94)$

\begin{tabular}{|c|c|c|c|c|c|c|}
\hline \multirow[b]{2}{*}{ Risk factors for NIHL } & \multicolumn{3}{|c|}{ Male (\%) } & \multicolumn{3}{|c|}{ Female (\%) } \\
\hline & Undergraduate & Graduate & Faculty/Staff & Undergraduate & Graduate & Faculty/Staff \\
\hline $\begin{array}{l}\text { Subjects that reported listening to devices } \\
\text { for more than } 4 \text { hours } / \text { day }^{*}\end{array}$ & 39 & 40 & 18 & 18 & 18 & 50 \\
\hline Users of any type of headphones* & 91 & 85 & 55 & 94 & 94 & 50 \\
\hline $\begin{array}{l}\text { Subjects that reported listening at } \\
\text { "somewhat loud" or "very loud" volume } \\
\text { levels" }\end{array}$ & 70 & 45 & 27 & 35 & 24 & 17 \\
\hline Reported at least 1 symptom of hearing loss & 30 & 50 & 36 & 35 & 29 & 50 \\
\hline $\begin{array}{l}\text { Subjects were not concerned that } \\
\text { entertainment devices could cause damage }\end{array}$ & 22 & 10 & 9 & 18 & 18 & 0 \\
\hline Subjects that have not heard of NIHL & 23 & 40 & 18 & 6 & 31 & 17 \\
\hline Subjects that believe NIHL is reversible ${ }^{\dagger}$ & 27 & 5 & 0 & 0 & 3 & 1 \\
\hline
\end{tabular}

NIHL, noise-induced hearing loss.

${ }^{*} P<.05$ for comparisons of responses from each academic level for both genders.

${ }^{\dagger} P<.05$ for comparisons of responses from each academic level for males only.

ing loss (Table 1) as well as to compare the numbers of subjects in each group that missed tones in the hearing screening (Figure 1). Data analysis was performed with SPSS (Chicago, IL).

\section{Results}

Almost all participants used a cell phone, followed by a laptop computer with a DVD player. Apple iPods were the third most frequently used category of device and were used disproportionately by undergraduate students (60\% versus $24 \%$ faculty/ staff; $P<.04)$. In terms of total devices used, 11 participants used one device, 23 used 2 devices, 50 used 3 devices, and 12 participants used 4 devices. Undergraduate (39\% males, $18 \%$ females) and graduate $(40 \%$ males, $18 \%$ females) males were more likely to listen to PMPs for more than 4 hours/day, whereas more than twice as many female faculty/staff reported listening for long periods (50\% female, $18 \%$ male). Only $5 \%$ of undergraduates and $27 \%$ of graduate students reported listening for 1 hour or less daily, whereas $41 \%$ of faculty staff reported short listening duration $(P<$ $.05)$. Almost all undergraduates $(92.5 \%)$ and graduate students $(89 \%)$ listened to music through headphones, compared with $55 \%$ of faculty and staff $(P<.02)$, with no difference between the genders. Despite using headphones, undergraduate students (55\%) reported listening "somewhat loud" or "very loud," compared with $35 \%$ of graduate students and $23.5 \%$ of faculty/staff $(P<.005)$. Undergraduate males (70\%) were most likely to report listening at loud volume levels whereas only $27 \%$ of male faculty/staff reported loud levels $(P<$ $.079)$, and $35 \%$ of female undergraduates reported loud volume compared with $17 \%$ of faculty/staff females $(P<.067)$. These results are summarized in Table 1 .

Overall, the majority of participants were at least slightly concerned about hearing loss with aging (15\% were "not concerned") and reported at least one symptom related to a hearing problem since initiation of use of their PMP (37\% reported no symptoms). The majority of participants were also concerned with hearing loss related to use of their devices (24\% were "not concerned"). There was no relationship between concern that entertainment devices could cause damage and self-reported volume level or listening duration. More than two thirds of faculty/staff (71\% male, $67 \%$ female) did not realize that noise-induced hearing loss is not reversible, compared with just less than half of undergraduate (46\% male, $42 \%$ female) and graduate (40\% male, $47 \%$ female) students. As shown in Table 1 , there was a statistically significant difference between the percentage of males at each academic level that believed that NIHL is reversible $(P<.009)$. The most likely actions taken in the past and contemplated in the future to protect hearing from noise-induced damage were lowering the volume and limiting amount of listening time; there was a significant level of concurrence between past and future actions to protect hearing $(P<.01)$. 

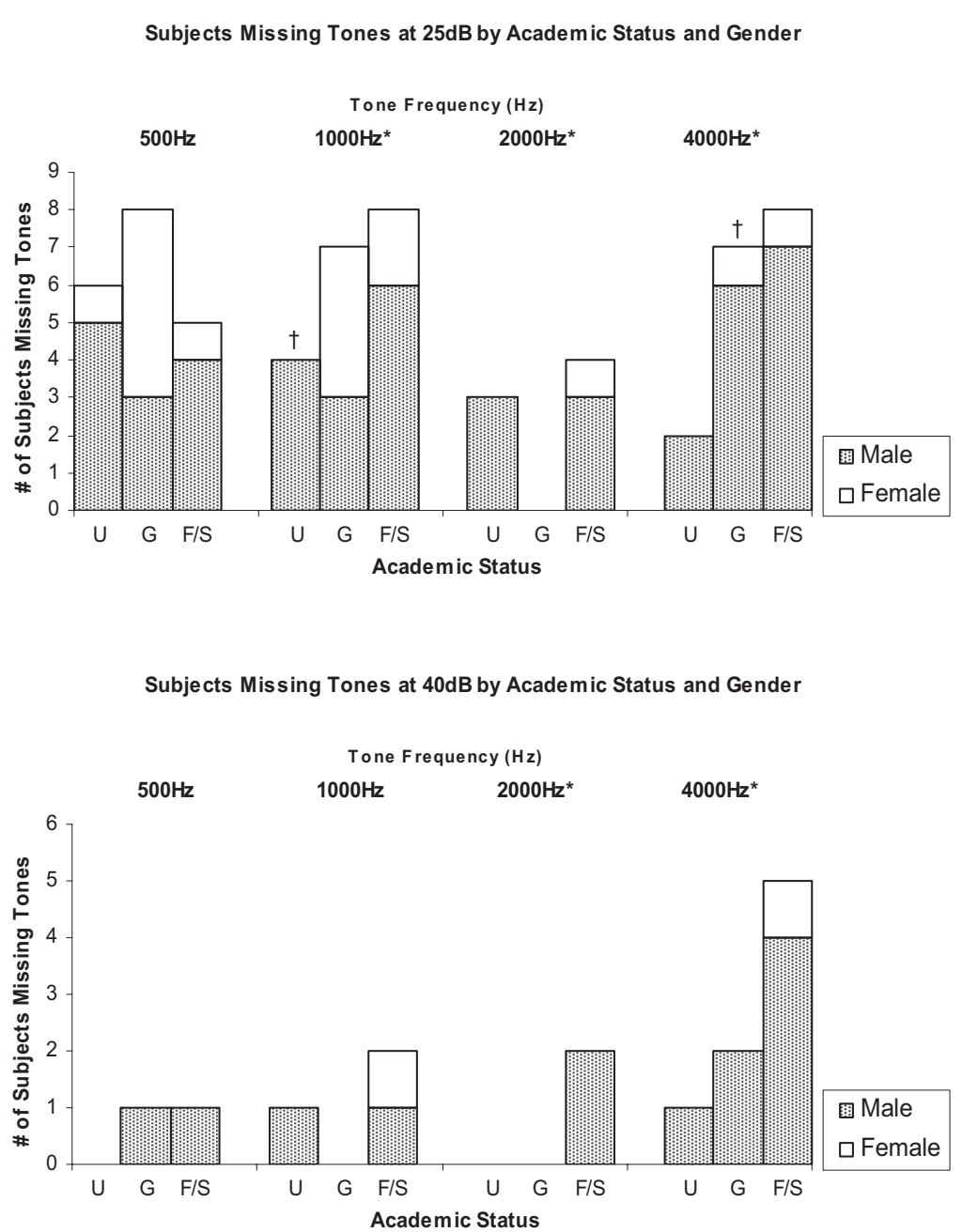

Figure 1. Number of participants not responding to tones in the right ear. Bars represent the number of males and females missing a tone at either $25 \mathrm{~dB}$ hearing level (HL) (typically heard by adults, top) or $40 \mathrm{~dB}$ HL (used to screen for mild hearing loss) at 1 of 4 frequencies found commonly in speech for undergraduate students (U; $n=$ 40), graduate students $(G ; n=37)$, and faculty/staff $(F / S ; n=17) \cdot \chi^{2}$ tests were performed for comparisons within gender groups by academic status. $* P<.05$ for comparisons between academic levels; $\uparrow P<.07$ for comparisons between genders.

The majority of participants were interested in learning about the prevention of noise-induced hearing loss $(73 \%)$, were aware of this phenomenon $(76 \%$ total, males, males more often than females), and would be willing to wear a hearing aid or assistive device (52\%). Most participants reported few sources of information on noise-induced hearing loss, and $40 \%$ felt their primary care physician should worry more about their hearing and prevention. Participants with concerns about hearing loss with aging were more likely to ascribe to a more active role for their primary physician on this issue $(P<.01)$.
A profile of hearing acuity at $25 \mathrm{~dB}$ and $40 \mathrm{~dB}$ for the right ear at $500 \mathrm{~Hz}$ (approximately the frequency of a car horn), $1000 \mathrm{~Hz}, 2000 \mathrm{~Hz}$, and $4000 \mathrm{~Hz}$ (nearly the sound of the highest note on a piano) is shown in Figure 1 within gender groups for each level of academic status. The human ear is most sensitive to sounds from $500 \mathrm{~Hz}$ to $4000 \mathrm{~Hz}$, and these frequencies are most common in human speech.

Within the undergraduate group at $25 \mathrm{~dB}, 15 \%$ missed the $500 \mathrm{~Hz}$ tone, $10 \%$ missed at $1000 \mathrm{~Hz}$, $7.5 \%$ missed at $2000 \mathrm{~Hz}$, and $5 \%$ missed at 4000 $\mathrm{Hz}$. There was a statistically significant difference 
in the number of male and female undergraduate students that missed the $1000 \mathrm{~Hz}$ tone at $25 \mathrm{~dB}$ $(P<.07)$. No undergraduate students missed $40 \mathrm{~dB}$ tones at $500 \mathrm{~Hz}$ and $2000 \mathrm{~Hz}$, and only $2.5 \%$ of students missed at $1000 \mathrm{~Hz}$ and $4000 \mathrm{~Hz}$. A greater percentage of graduate students missed $25 \mathrm{~dB}$ tones at $500 \mathrm{~Hz}(22 \%), 1000 \mathrm{~Hz}(19 \%)$, and $4000 \mathrm{~Hz}$ (19\%), but fewer missed at $2000 \mathrm{~Hz}(0 \%)$. There was a statistically significant difference in the number of male and female graduate students that missed the $4000 \mathrm{~Hz}$ tone at $25 \mathrm{~dB}(P<.062)$. No graduate students missed $40 \mathrm{~dB}$ tones at $1000 \mathrm{~Hz}$ or $2000 \mathrm{~Hz}$, but $2.7 \%$ missed at $500 \mathrm{~Hz}$ and $5.41 \%$ missed at $4000 \mathrm{~Hz}$. More faculty and staff missed tones at all levels for both sound intensities, with males missing more tones than females at all tones. At $25 \mathrm{~dB}, 29.41 \%$ missed at $500 \mathrm{~Hz}, 47.06 \%$ at $1000 \mathrm{~Hz}, 23.5 \%$ at $2000 \mathrm{~Hz}$, and $47.06 \%$ at 4000 Hz. A high percentage of faculty and staff members missed the $40 \mathrm{~dB}$ tone at $4000 \mathrm{~Hz}(29 \%)$, but only $6 \%$ missed at $500 \mathrm{~Hz}$ and $12 \%$ at $1000 \mathrm{~Hz}$ and $2000 \mathrm{~Hz}$. Overall, faculty/staff had more measurable hearing impairment than the other age groups, as indicated in Figure 1. This age-dependent difference in hearing acuity was statistically significant in many cases: $1000 \mathrm{~Hz} / 25 \mathrm{~dB}(P<.015), 2000$ $\mathrm{Hz} / 25 \mathrm{~dB}(P<.016), 2000 \mathrm{~Hz} / 40 \mathrm{~dB}(P<.016)$, $4000 \mathrm{~Hz} / 25 \mathrm{~dB}(P<.002), 4000 \mathrm{~Hz} / 40 \mathrm{~dB}(P<$ $.006)$. The total number of devices used, amount of time of use of devices, and total symptoms were not associated with any of the measures of hearing acuity.

Levels of cerumen were higher for students than faculty and staff. Nearly $24 \%$ of undergraduates tested had some level of cerumen and $8 \%$ had moderate to heavy levels. A similar percentage of graduate students had observable cerumen with fewer having moderate to heavy levels (4\%). Thirteen percent of faculty and staff had detectable cerumen and $5 \%$ had moderate to heavy levels. Cerumen levels were statistically associated at the $P<.025$ level or lower with missed tones at $25 \mathrm{~dB}$ for all 4 frequencies plus $40 \mathrm{~dB}$ at $4000 \mathrm{~Hz}$. People with medium or heavy levels of cerumen accounted for $58 \%(25 \mathrm{~dB}$ at $2000 \mathrm{~Hz}$ and $40 \mathrm{~dB}$ at $4000 \mathrm{~Hz}), 75 \%(25 \mathrm{~dB}$ at $500 \mathrm{~Hz}), 87 \%(25$ $\mathrm{dB}$ at $1000 \mathrm{~Hz})$, and $100 \%(25 \mathrm{~dB}$ at $4000 \mathrm{~Hz})$ of those missing the given tone.

\section{Discussion}

This study evaluated listening habits of a self-selected sample of students, faculty, and staff against actual hearing acuity. Before discussing the results of this study, limitations in methodology will be addressed. Use of a fitness facility may suggest that the participants were healthier and more attuned to concerns about health than people not electing to exercise. Furthermore, there is limited evidence that regular moderate exercise protects hearing so the hearing acuity of these subjects may be better than others that do not exercise. ${ }^{16}$ More young adults in this study listened at somewhat loud or very loud volume compared with a recent a 2005 survey completed by the American School Health Association (55\% versus $41 \%$ ) and for longer times during the day $(30 \%$ for 4 or more hours a day versus $11 \%$ ), but this estimation of the length of noise exposure is confounded by the fact that we did not inquire as to other sources of noise exposure. Thus, the total context of exposure to noise is not known. Also unknown is the absolute sound intensity that listeners use and the length of each listening period within each day. In the interest of confidentiality, participants were not asked for their exact age or general social history.

Unlike other recent samples, people volunteering for this study were by and large both aware of and concerned about NIHL. Despite being more alert to the issue, approximately half of these same people in the current study were either inaccurate $(12 \%)$ or uninformed $(37 \%)$ about the reversibility of NIHL with medical intervention. The misconception that hearing loss is reversible may stem from technological and performance improvements in hearing aids and other assistive devices. Progress has been made in terms of quality and availability of hearing aids for the treatment of mild sensorineural hearing loss, and the success of cochlear implants has greatly enhanced hearing capacity for listeners with severe to profound sensorineural hearing loss. ${ }^{17}$ In addition, some basic scientists are pursuing techniques to regenerate, repair, and protect auditory hair cells, but a clinical therapy is not yet a possibility. ${ }^{18}$ Despite the success of these therapies, partially restored listening performance does not match the performance of the intact auditory system; even mild hearing loss can have a devastating impact on quality of life, causing depression, social isolation, poor physical functioning, and decreased self-sufficiency. ${ }^{19}$

A majority of students reported using a portable entertainment device with headphones and listening for at least 3 hours/day, whereas just less than 
$50 \%$ knowingly listen at levels that they consider somewhat loud or loud. In addition, $77 \%$ of students reported some level of concern about the possibility of hearing damage from using PMPs. The fragility of the inner ear mechanism against loud noise has been documented in the medical and scientific literature for almost 50 years, ${ }^{10}$ but the long hours of daily use and loud volume indicate that many students may not fully understand the effects of chronic noise exposure.

A statistically significant relationship was not found between PMP use and acute symptoms of hearing loss in this study. However, information from the National Health and Nutrition Survey conducted from 1999 to 2004 (NHANES) offers grounds for concern for the trends in hearing acuity measured in this sample. The average hearing minimal thresholds or minimal perceptible level of sound at frequencies that are found in speech for adults ages 20 to 29 are as follows: $<15 \mathrm{~dB}$ at 500 $\mathrm{Hz}, 10 \mathrm{~dB}$ at $1000 \mathrm{~Hz},<15 \mathrm{~dB}$ at $2000 \mathrm{~Hz}$, and $<15 \mathrm{~dB}$ for females and $25 \mathrm{~dB}$ for males at 4000 Hz. ${ }^{14}$ In our study, up to $22 \%$ of students did not meet these thresholds (Figure 1). Although older individuals were more likely to miss tones at all frequencies and sound intensities, significant numbers of young people also missed tones (ie, $15 \%$ of undergraduates missed the $500 \mathrm{~Hz}$ tone at $25 \mathrm{~dB}$ ).

Cerumen impaction may partially explain the increased incidence of missed tones in younger (undergraduate/graduate students) versus older (faculty/staff) subjects. One of 4 undergraduate students had an easily visible amount of cerumen in the external auditory meatus, whereas only $13 \%$ of faculty had visible cerumen. Furthermore, there is a statistically significant relationship between the amount of cerumen observed and the incidence of missed tones at $25 \mathrm{~dB}$. Primary care providers should help people understand that cerumen can be a considerable impediment to sound perception. ${ }^{20}$ Better appreciation for proper cleaning technique of the outer ear may increase hearing acuity and reduce the urge for listeners to increase the volume level on PMPs. Readily available handouts from web sites such as the one referenced (http://www.aafp.org/afp/20070515/1530ph.html) here could be used in this patient education process.

Primary care and family medicine physicians are well positioned to disseminate information to patients on the dangers of loud noise and methods of preventing NIHL. Advice on noise could be incor- porated into lifestyle guidance offered by primary care providers on other aspects of lifestyle related to health. In fact, hearing problems are known to be associated with behaviors broadly detrimental to health (eg, smoking, ${ }^{21}$ lack of exercise, ${ }^{16}$ and poor dental health ${ }^{22}$ ), diabetes, ${ }^{23}$ and cardiovascular disease. ${ }^{24}$ In particular, young patients would benefit from knowing recommended volume levels for PMPs, such as the recently published sound intensities for specific headphones and various devices by Portnuff and Fligor. ${ }^{25}$ For most entertainment devices and headphone types, $70 \%$ of the volume level represents roughly $85 \mathrm{~dB}$, or the acceptable limit for sound intensity. The same study concluded that when listening at $100 \%$ volume, there is only an 18-minute safe exposure time with overthe-ear supra aural earphones, 5-minute safe exposure time for earbud and iPod stock earphones, and 3-minute safe exposure time for isolator-type earbuds. To limit the cumulative amount of noise exposure, listeners should decrease the length of time that PMPs are used, decrease the volume, or use ear protection. Furthermore, there is evidence that young people would be more willing to consider hearing protection if they were fully aware of the impact of NIHL. ${ }^{26}$ Informing patients about the physiologic and psychosocial effects of hearing loss may encourage them to proactively protect themselves from noise damage.

This work was supported by the Gateway Program for Scholarly Activity in Family Medicine. The authors thank Susan Lafferty for her assistance with Institutional Review Board approval, Robyn Deterding at Campus Recreation, and Pavni Mehrotra for her help with data collection.

\section{References}

1. National Institute of Deafness and other Communication Disorders. Noise-induced hearing loss. Available at http://www.nidcd.nih.gov/nidcdinternet/ Templates/Internet TopicNavigationFS.aspx?NRMODE $=$ Published $\&$ NRNODEGUID $=\{448 F 1432-$ 04EF-416E-9F1A-4F53DA05DA4C\}\&NRORIGINALURL $=$ /health/hearing/noise.asp\&NRCACHEHINT $=$ NoModifyGuest\#what. Updated 2007. Accessed 4 March 2008.

2. Niskar AS, Kieszak SM, Holmes AE, Esteban E, Rubin C, Brody DJ. Estimated prevalence of noiseinduced hearing threshold shifts among children 6 to 19 years of age: The third national health and nutrition examination survey, 1988-1994, United States. Pediatrics 2001;108:40-3.

3. Arlinger S. Negative consequences of uncorrected 
hearing loss-a review. Int J Audiol 2003;42 Suppl 2:2S17-20.

4. Biassoni EC, Serra MR, Richtert U, et al. Recreational noise exposure and its effects on the hearing of adolescents. Part II: Development of hearing disorders. Int J Audiol 2005;44:74-85.

5. Serra MR, Biassoni EC, Richter U, et al. Recreational noise exposure and its effects on the hearing of adolescents. Part I: An interdisciplinary long-term study. Int J Audiol 2005;44:65-73.

6. Holgers KM, Pettersson B. Noise exposure and subjective hearing symptoms among school children in Sweden. Noise Health 2005;7:27-37.

7. Meyer-Bisch C. Epidemiological evaluation of hearing damage related to strongly amplified music (personal cassette players, discotheques, rock concerts)high-definition audiometric survey on 1364 subjects. Audiology 1996;35:121-42.

8. Fligor BJ, Cox LC. Output levels of commercially available portable compact disc players and the potential risk to hearing. Ear Hear 2004;25:513-27.

9. Mostafapour SP, Lahargoue K, Gates GA. Noiseinduced hearing loss in young adults: The role of personal listening devices and other sources of leisure noise. Laryngoscope 1998;108:1832-9.

10. Engstrom H, Ades HW. Effect of high-intensity noise on inner ear sensory epithelia. Acta Otolaryngol Suppl 1960;158:219-29.

11. Schmuzigert N, Fostiropoulos K, Probst R. Longterm assessment of auditory changes resulting from a single noise exposure associated with non-occupational activities. Int J Audiol 2006;45:46-54.

12. Chung JH, Des Roches CM, Meunier J, Eavey RD. Evaluation of noise-induced hearing loss in young people using a web-based survey technique. Pediatrics 2005;115:861-7.

13. Zogby J. Survey of teens and adults about the use of personal electronic devices and head phones. American Speech-Language-Hearing Association. Available at http://www.asha.org/about/news/atitbtot/ zogby.htm. Updated 2003. Accessed 3 February 2008.

14. Murphy WJ, Christa T, Stephenson M. ASA 151st meeting lay language papers-hearing levels in US adults. Available at http://www.acoustics.org/press/ 151st/Murphy.html. Updated 2006. Accessed 3 February 2008 .
15. Bienvenue GR, Michael PL, Chaffinch JO. Reference threshold sound pressure levels for the welch allyn AudioScope. J Acoust Soc Am 1984;75:188792.

16. Cristell M, Hutchinson KM, Alessio HM. Effects of exercise training on hearing ability. Scand Audiol 1998;27:219-24.

17. Kim HH, Barrs DM. Hearing aids: A review of what's new. Otolaryngol Head Neck Surg 2006;134: 1043-50.

18. Feghali JG, Lefebvre PP, Staecker H, et al. Mammalian auditory hair cell regeneration/repair and protection: A review and future directions. Ear Nose Throat J 1998;77:276, 280, 282-5.

19. Chia EM, Wang JJ, Rochtchina E, Cumming RR, Newall P, Mitchell P. Hearing impairment and health-related quality of life: The blue mountains hearing study. Ear Hear 2007;28:187-95.

20. McCarter DF, Courtney AU, Pollart SM. Cerumen impaction. Am Fam Physician 2007;75:1523-8.

21. Cruickshanks KJ, Klein R, Klein BE, Wiley TL, Nondahl DM, Tweed TS. Cigarette smoking and hearing loss: The epidemiology of hearing loss study. JAMA 1998;279:1715-9.

22. Lawrence HP, Garcia RI, Essick GK, et al. A longitudinal study of the association between tooth loss and age-related hearing loss. Spec Care Dentis 2001; 21:129-40

23. Diaz de Leon-Morales LV, Jauregui-Renaud K, Garay-Sevilla ME, Hernandez-Prado J, Malacara-Hernandez JM. Auditory impairment in patients with type 2 diabetes mellitus. Arch Med Res 2005;36:50710.

24. Torre P, 3rd, Cruickshanks KJ, Klein BE, Klein R, Nondahl DM. The association between cardiovascular disease and cochlear function in older adults. J Speech Lang Hear Res 2005;48:473-81.

25. Portnuff CDF, Fligor BJ. NIHL meeting lay language papers - sound output levels of the iPod and other MP3 players: Is there potential risk to hearing? Available at http://www.hearingconservation.org/ docs/virtualPressRoom/portnuff.htm. Updated 2006. Accessed 3 February 2008.

26. Daniel E. Noise and hearing loss: A review. J Sch Health 2007;77:225-31. 